\title{
PROJECT MANAGEMENT USING CRITICAL PATH METHOD (CPM): A PRAGMATIC STUDY
}

\author{
A. M. ALIYU \\ (Received 31 August 2012; Revision Accepted 25 October 2012)
}

\begin{abstract}
Traditional techniques of decision-making have hindered the technical efficiency of most professionals and executors of the public project in many developing countries such as Nigeria. The use of Gantt chart in project planning has continued to increase as a source of last resort in spite of its severe limitations for ineffective project management and delivery. CPM has gained widespread commendation and acceptance in the developed countries. This technique is yet to gain any appreciable acceptance for implementation of public projects in Nigeria. Professionals and executors of public projects in Nigeria have remained conscientiously to the Gantt chart. In order to address this problem of project planning, the CPM was applied to "construction of a complex building at Federal University of Technology, Yola." This paper describes a specific case study with real data and an application. The results show the effectiveness of the CPM in, planning, scheduling, and organizing, coordinating, managing, and controlling of project time and cost. The study concludes by arguing that, CPM is not difficult to apply and when applied it improves inter-departmental communications, gives clear definition of responsibilities and minimizes the occurrence of crisis management.
\end{abstract}

KEYWORDS: Developing countries, CPM, Nigeria, construction.

\section{INTRODUCTION}

Planning, organizing and controlling are the three most important functions of the executive. Of these three, planning is the most intellectually demanding. Hence any scientific aid to the executive in the performance of the planning function, especially the planning of projects, is always a welcome relief. Since the 1900s, scientific models which aid in the planning, management, costing, and execution of large-scale, one-off, complex projects have been made available to decision-makers. One of the such is Gantt chart. Gantt chart was one of the earliest models made available to aid in project work (Chasse and Acquilano 1973). Gantt chart came into use through Henry Gantt, in the early 1900's (Nworuh 2002). As at then it was used worldwide for project planning, scheduling, coordination and control. Gantt chart (or bar chart) method of project planning has impeded the technical efficiency of most professionals and executors of public and private projects in many developing countries, including Nigeria. From the 1950s however, the need for more efficient and effective execution of large-scale, one-off, complex projects and the experiences gained from the application of operational research (O.R) during world war II gave renewed impetus to research for improved models for project management (Idama 1999).

A Technique for project planning was developed in the late 1950s known as Critical Path Method (CPM). CPM had emerged to support and serve as alternatives to Gantt chart.
Scientists working in the Du Pont Company in conjunction with scientists from UNIVAC Division of Remington Rand developed CPM. They were working on a maintenance project, for Du Pont's chemical plants. More than five decades after the CPM technique has gained worldwide commendation and acceptance in the developed countries, this technique is yet to acquire any appreciable acceptance for the implementation of public and private projects in Nigeria and in most other parts of the developing world. This is as a result of failures to adopt and implement the scientific systems analysis developed over the years by researchers and used in most advanced countries. Studies and researches enumerate the possible causes of this breach to include inadequate knowledge and experience of the technique, lack of adoption or reluctance to adopt a new technological innovation as well as cost of operations (Bassey and Chigb 2002).

Professionals and executors of private and public projects in Nigeria and other developing countries have been trapped devotedly to the Gantt chart regardless of its severe shortcoming in effective project management and delivery. The number of abandoned or uncompleted projects that litter the length and breadth of Nigeria is a clear indication of ineffectiveness and the, inability to plan, manage, and execute complex projects. These are besides the behavioral problems that hinder the implementation of public project in Nigeria. Nevertheless, the practice and use of Gantt chart is an additive to the general problem.

A. M. Aliyu, Department of Statistic/Operations Research, School of Pure and Applied Sciences, Modibbo Adama University of Technology, P. M. B. 2076, Yola, Adamawa State, Nigeria. 
The inability to plan, manage and successfully execute projects can be appreciated from the following few examples:

1) According to Idama (1999), the third mainland bridge project was initiated in1972tobecompleted in 1976, after years of abandonment; the project was completed in 1991at exceedingly high cost compared to the 1972 price.

2) The Gugba Aerostat balloon project took off in 1975 at the cost of five hundred and sixty million Naira. It was to be completed in 1980; it was abandoned in 1978 after it had consumed one hundred and forty million naira.

3) Contract for the first face of the metro-line project in Lagos was awarded in 1980 at the cost of six hundred and ninety-eight million Naira. The project was to be completed in July 1986. It was abandoned after more than one third of the work was done and about three hundred and fifty million Naira spent in its execution. The succeeding government later scraped the project. Since then successive administrations, including the present democratically elected government have thought of resustating the metro-line project.

4) Gubi dam project is a water reservoir construction project. The executors of the contract were Impresit Bakolori (Nig.) Limited, and Impresit of Milan (one of the world's largest civil engineering companies). The project commenced in February 1990 and was expected to be completed in 140 weeks (i.e. October, 1992).

This particular project was chosen for illustration because it was commissioned during the construction era in Nigeria (this is the dominant era of abandoned, uncompleted or delayed projects in Nigeria), and it was a relatively complex project requiring meticulous planning, costing, management and execution.

5) The Mista Ali Electrification project is a smallscale project. It was chosen to illustrate the application of CPM in the execution of a smallscale project. The contract for this project was awarded to Simak Limited Jos Plateau State, Nigeria although the project was actually executed by Adinluck Construction limited. The project was executed in 120 days although under the terms of the contract it was expected to be completed in 80 days. From the CPM Network, the project can be completed in approximately 72 days. It is clear then that the contractual obligation of completing the project in 80 days can in fact be met. However, this project actually took 120 days to be completed!

6) Other abandoned projects include the controversial Ajaokuta Steel project, the dredging of River Niger and, all sorts of projects that are abandoned in Nigeria. Some of these projects were later completed at staggering costs over the original estimate.

Additionally, efforts made towards reorienting public project executors to the use of CPM have met with little success. Thus use of Gantt chart has continued in public projects implementation.

Meanwhile, the recognition and unenviable level of commitment of public projects executors to the CPM had hitherto remained very low. It is important to note that, the malfunctioning of a project through weak project management methods carries two implications for the economy. First and foremost, is the wastage of scare resources used in the execution of projects, and the denial of the opportunity for other projects to come to life through stronger methods It is therefore better for a nation not to get on a project implementation than to commence and stop (Inyanga 1999). The ugly situation about the development of project in Nigeria is that a lot of these projects stop as soon as the policies guiding their execution are approved. Most of the projects become unfinished and thus become wasteful while a few finished ones are not properly maintained in the long run. This incessant reluctance to adopt CPM by Nigerian public project executors, and the endless stoppage of important project due to limitation of time, quality and performance standard of public projects being carried out with the antiquated traditional techniques; persistent wastages of national resources and underdevelopment of Nigeria are what underline the need for this study.

\section{Materials and Methods}

\subsection{The Project Site}

The site is situated in the main campus of Federal University of Technology, Yola.The project is a gigantic structure that contains offices and lecture Rooms.

The SMIT project under study was schedule to commence in the second week of August 2002 to be completed in the second week of June 2003. The initial contract sum was one hundred and twenty-four million Nigerian Naira. The project was abandoned. It was later revoked. Finally, it was reviewed to one hundred and seventy five million Naira and latter to one hundred and eighty-eight million Naira, by successive administrators. Gantt chart was the only job-scheduling tool available to project manager. Up to the time of this study the project is yet to be completed.

\subsection{Method of Data Collection}

The source of data was purely secondary. A visit was conducted to the project site, and physical contact was made with the project manager on site. A program chart (Gantt chart) was provided (Appendix A). A professional Quantity Surveyor decoded and interpreted the chart. There were twenty-five activities in the program chart. One activity was added later. Activity duration was estimated on weekly basis. Code was used to denote an activity i.e $A_{1} \ldots A_{26}$. Table 1 below shows the description of each 
activity and its relationships. Normal time was extracted from the chart. Crash time was extracted from the Normal Time. A percentage value is allocated to each activity. Normal cost is the initial contract sum. Crash cost is the final reviewed contract sum. Multiplying the percentage given on the contract sum and have normal cost and crash cost for the twenty-six activities. Table 2 below shows these data and crash cost. The Table was obtained using Microsoft Excel.

\subsubsection{Activity Relationship}

Code is used to denote an activity i.e $A_{1}, \ldots A_{26}$. The table below has twenty-six jobs. Jobs were extracted from the Gantt chart (Appendix A). Activity relationship was clearly defined by the quantity surveyor

Table 1: Activity Classification and Relationships

\begin{tabular}{|c|c|c|c|}
\hline $\mathbf{S} / \mathbf{n}$ & Description of Activity & Code & Predecessor \\
\hline $\begin{array}{l}1 . \\
2 . \\
3 . \\
4 . \\
5 . \\
6 . \\
7 . \\
8 . \\
9 . \\
10 . \\
11 . \\
12 . \\
13 . \\
14 . \\
15 . \\
16 . \\
17 . \\
18 . \\
19 . \\
20 . \\
21 . \\
22 . \\
23 . \\
24 . \\
25 . \\
26 .\end{array}$ & $\begin{array}{l}\text { Site Clearing } \\
\text { Setting out } \\
\text { Excavation } \\
\text { Blinding \&Foundation Footing } \\
\text { Block work/Filing } \\
\text { Column/Beam in Foundation } \\
\text { Back filing compaction } \\
\text { Mechanical work/Over site concrete } \\
\text { Block work/Lintel } \\
\text { Floor slab/Beams/Columns } \\
\text { Block work } 1^{\text {st }} \text { floor } \\
\text { Roof Beam/Head course } \\
\text { Plaster/Rendering } \\
\text { Structural/Roof Trusses } \\
\text { Roofing/Ceiling Work } \\
\text { Electrical/conduit/circuit } \\
\text { Mechanical pipe work } \\
\text { Door \& Window Frames } \\
\text { Finishes \& paintings } \\
\text { Mechanical Fittings } \\
\text { Electrical Fittings } \\
\text { Door \& Window Leaves } \\
\text { Soakage Systems } \\
\text { Testing Facilities } \\
\text { Remedy } \\
\text { Demobilization }\end{array}$ & $\begin{array}{l}A_{1} \\
A_{2} \\
A_{3} \\
A_{4} \\
A_{5} \\
A_{6} \\
A_{7} \\
A_{8} \\
A_{9} \\
A_{10} \\
A_{11} \\
A_{12} \\
A_{13} \\
A_{14} \\
A_{15} \\
A_{16} \\
A_{17} \\
A_{18} \\
A_{19} \\
A_{20} \\
A_{21} \\
A_{22} \\
A_{23} \\
A_{24} \\
A_{25} \\
A_{26}\end{array}$ & $\begin{array}{l}A_{1} \\
A_{1} \\
A_{2} \\
A_{3} \\
A_{3} \\
A_{4} \\
A_{6} \\
A_{6} \\
A_{7} \\
A_{10} \\
A_{11} \\
A_{9} \\
A_{13} \\
A_{13} \\
A_{8} \\
A_{11} \\
A_{14} \\
A_{15} \\
A_{15} \\
A_{20} \\
A_{19} \\
A_{12}, A_{17} \\
A_{22} \\
A_{24} \\
A_{5}, A_{16}, A_{18}, A_{21}, A_{23} A_{25}\end{array}$ \\
\hline
\end{tabular}

Using the following expression and get:

Normal Cost $=$ Percentage $\times$ Contract Sum

Crash cost $=$ percentage $\times$ Contract Sum

Normal Time - Crash Time $=$ Crash Limit

$\underline{\text { Crash Cost }- \text { Normal Cost }}=$ Crash cost per week Crash Limit 
Table 2: Crash time-cost table

\begin{tabular}{|c|c|c|c|c|c|c|c|}
\hline Activity & Percentage & \begin{tabular}{|l} 
Normal \\
Time
\end{tabular} & \begin{tabular}{|l} 
Crash \\
Time
\end{tabular} & Normal Cost & Crash Cost & Crash Limit & Crash Cost/week \\
\hline A1 & 1 & 3 & 1 & $1,240,000$ & $1,880,000$ & 2 & 320,000 \\
\hline A2 & 0.5 & 2 & 2 & 620,000 & 940,000 & 0 & \#DIV/0! \\
\hline A3 & 1.5 & 3 & 2 & $1,860,000$ & $2,820,000$ & 1 & 960,000 \\
\hline $\mathrm{A} 4$ & 3 & 3 & 2 & $3,720,000$ & $5,640,000$ & 1 & $1,920,000$ \\
\hline A5 & 2 & 3 & 3 & $2,480,000$ & $3,760,000$ & 0 & \#DIV/0! \\
\hline A6 & 5 & 4 & 3 & $6,200,000$ & $9,400,000$ & 1 & $3,200,000$ \\
\hline A7 & 2 & 5 & 4 & $2,480,000$ & $3,760,000$ & 1 & $1,280,000$ \\
\hline A8 & 8 & 6 & 5 & $9,920,000$ & $15,040,000$ & 1 & $5,120,000$ \\
\hline A9 & 6 & 5 & 4 & $7,440,000$ & $11,280,000$ & 1 & $3,840,000$ \\
\hline A10 & 7 & 5 & 4 & $8,680,000$ & $13,160,000$ & 1 & $4,480,000$ \\
\hline A11 & 6 & 5 & 4 & $7,440,000$ & $11,280,000$ & 1 & $3,840,000$ \\
\hline A12 & 4 & 5 & 5 & $4,960,000$ & $7,520,000$ & 0 & \#DIV/0! \\
\hline A13 & 9 & 12 & 10 & $11,160,000$ & $16,920,000$ & 2 & $2,880,000$ \\
\hline $\mathrm{A} 14$ & 3 & 3 & 2 & $3,720,000$ & $5,640,000$ & 1 & $1,920,000$ \\
\hline A15 & 2 & 2 & 2 & $2,480,000$ & $3,760,000$ & 0 & \#DIV/0! \\
\hline A16 & 13 & 16 & 13 & $16,120,000$ & $24,440,000$ & 3 & $2,773,333$ \\
\hline A17 & 5 & 5 & 4 & $6,200,000$ & $9,400,000$ & 1 & $3,200,000$ \\
\hline A18 & 5 & 6 & 4 & $6,200,000$ & $9,400,000$ & 2 & $1,600,000$ \\
\hline A19 & 4 & 5 & 5 & $4,960,000$ & $7,520,000$ & 0 & \#DIV/O! \\
\hline A20 & 4 & 4 & 3 & $4,960,000$ & $7,520,000$ & 1 & $2,560,000$ \\
\hline A21 & 3 & 3 & 2 & $3,720,000$ & $5,640,000$ & 1 & $1,920,000$ \\
\hline $\mathrm{A} 22$ & 2 & 3 & 2 & $2,480,000$ & $3,760,000$ & 1 & $1,280,000$ \\
\hline DUMMY & 0 & 0 & & 0 & 0 & 0 & \#DIV/0! \\
\hline A23 & 1 & 3 & 2 & $1,240,000$ & $1,880,000$ & 1 & 640,000 \\
\hline A24 & 1 & 1 & 1 & $1,240,000$ & $1,880,000$ & 0 & \#DIV/0! \\
\hline A25 & 1 & 1 & 1 & $1,240,000$ & $1,880,000$ & 0 & \#DIV/0! \\
\hline A26 & 1 & 2 & 1 & $1,240,000$ & $1,880,000$ & 1 & 640,000 \\
\hline Total & 100 & 115 & 91 & $124,000,000$ & $188,000,000$ & 24 & $44,373,333$ \\
\hline
\end{tabular}

\subsection{Method of Data Analysis}

Two method of were used in the analysis of data. One is enumerative method and the other is mathematical programming method.

\subsubsection{The Enumerative Method}

A computer application package known as TORA optimization system (Taha 2000) was used in the computation of CPM schedule (Appendices B, C, D). Appendix $B$ shows on page one normal time as original data. Activity symbol was assigned to identify an activity. Forward and backward pass computation results and bar graph were obtained using TORA software.

Appendix $\mathrm{C}$ shows on page one crash time as original data. Data was inputted into the computer packages, which yielded, forward and backward pass computations results and bar graph. Appendix D indicates the optimal results. All computation was carried out using TORA application package. 


\subsubsection{The Project Network}

The project Network is shown in Figure 1 below:

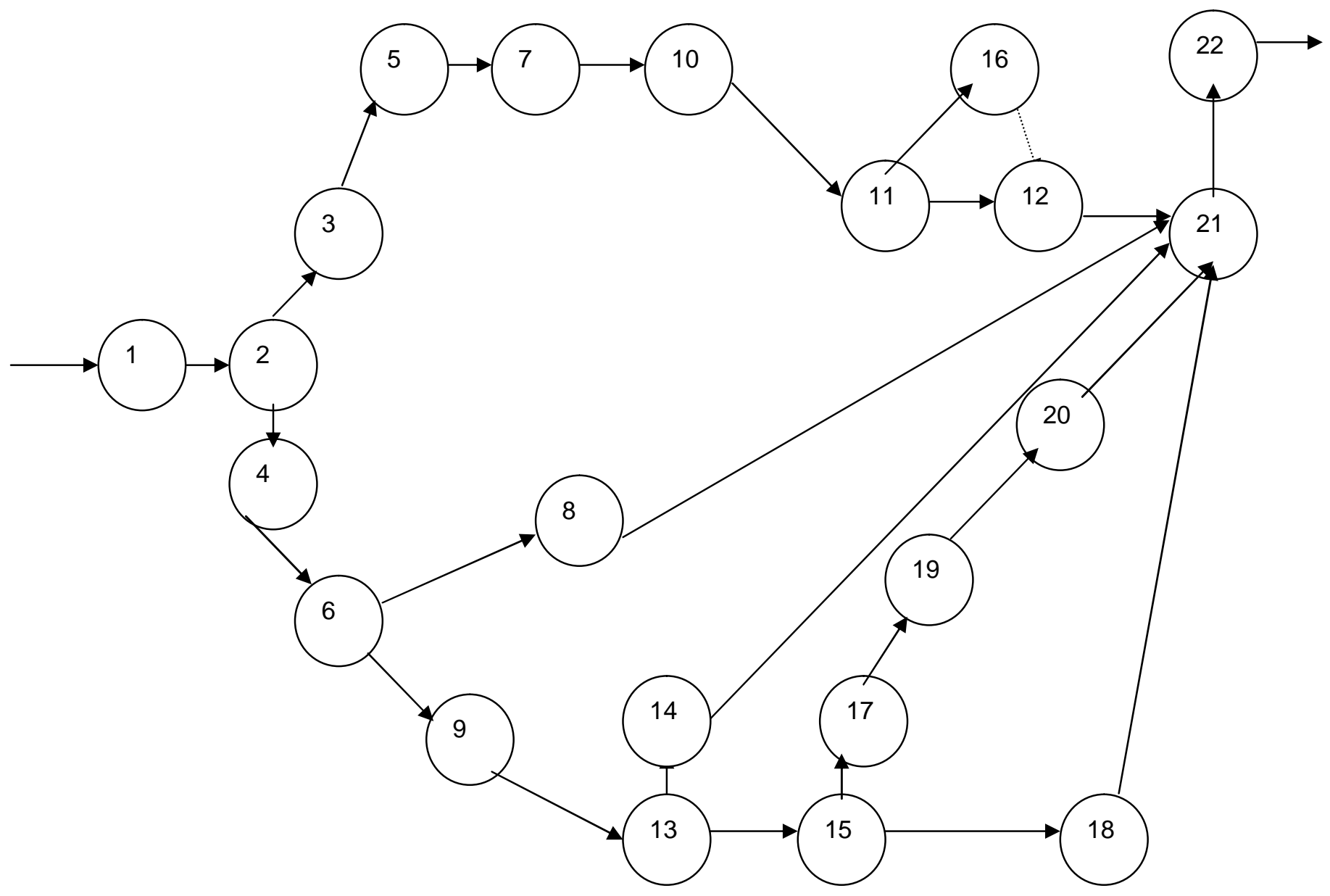

Figure 1: Network flow chart for the proposed School of Management and Information Technology (SMIT) complex at the Federal University of Technology, Yola

\subsubsection{Determining the Critical path/ project Duration}

The duration of the project is the time required on the critical path. For the SMIT project, the duration of the different paths is as calculated below:

Path 1: $\sum_{i}^{j}\left(D_{i, j}\right)=30$ weeks $\quad(i=1,2,3,5,7,10,11,16,12,21$, and $, j=2,3,7,10,11,12,21,22)$

Path 2: $\sum_{i}^{j}\left(D_{i, j}\right)=30$ weeks $(i=1,2,3,5,7,10,11,12,21$, and $, l=2,3,5,7,10,11,12,21,22)$

Path3: $\sum_{i}^{j}\left(D_{i, j}\right)=7$ weeks $(i=1,2,4,21$, and $, j=2,4,21,22)$

Path4: $\sum_{i}^{j}\left(D_{i, j}\right)=29$ weeks $(i=1,2,4,6,8,21$, and $, j=2,4,6,8,21,22)$

Path5: $\sum_{i}^{j}\left(D_{i, j}\right)=30$ weeks $\quad(i=1,2,4,6,9,13,14,21$, and $, j=2,4,6,13,14,21,22)$ 
Path6: $\sum_{i}^{j}\left(D_{i, j}\right)=32$ weeks $(i=1,2,4,6,9,13,15,17,19,20,21$, and $, j=2,4,6,9,13,15,17,19,20,21,22)$

Path7: $\sum_{i}^{j}\left(D_{i, j}\right)=37$ weeks $(i=1,2,4,6,9,13,15,18,21$, and $, j=2,4,6,9,13,15,18,21,22)$

- $\quad$ The critical path 6: $A_{1}, A_{3}, A_{6}, A_{9}, A_{13}, A_{15}, A_{19}, A_{22}, A_{24}, A_{25}$ and $A_{26}$.

The project duration is as follows:

Path 6

32 weeks

There is only one critical path in the network diagram fig. 1.

If all the jobs are done at their normal times, the project duration (length of the longest path) will be 41 weeks. Hence, under a "no crashing" schedule,

$$
\begin{aligned}
\text { Total project cost }=\sum_{i}^{j}\left[D_{i, j}\right]=\text { N124million } & (i=1,2,4,6,9,13,15,17,19,20,21) \\
& (j=2,4,6,9,13,15,17,19,20,21,22) .
\end{aligned}
$$

On the other hand, if all the jobs were crashed to their minimum time, then the project duration will be 32 weeks.

Under this schedule,

Total project cost $=\sum_{i}^{j}\left[D_{i, j}\right]=N 188$ million $(i=1,2,4,6,9,13,15,17,19,20,21)$

$$
(j=2,4,6,9,13,15,17,19,20,21,22)
$$

Using the normal times for the activities, the earliest and latest occurrence time. The project management problem is to determine the optimal duration of activities that will minimize the total project time and cost. Using the normal times for the activities, the earliest and latest occurrence times of the events $(i, j)$ are computed using TORA Optimization system software. The project completion time is 41 weeks, and the project network has one critical path. $1 \rightarrow 2 \rightarrow 4 \rightarrow 6 \rightarrow 9 \rightarrow 13 \rightarrow 15 \rightarrow 17 \rightarrow 19 \rightarrow 20 \rightarrow 21 \rightarrow 22$. The critica I activities are jobs $A_{1}, A_{3}, A_{6}, A_{9}, A_{13}, A_{15}, A_{19}, A_{22}, A_{24}$, $A_{25}$, and $A_{26}$. The total project cost under normal time is N124million.

\subsubsection{Crashing The Network}

The decision about which activity to crash depends on: the least cost, and how the extent to which a reduction in the project time and cost is needed. To reduce the project duration therefore, the activity cost slope must be inspected to see which activity can be reduced at the least cost; this will be done progressively until the total number of weeks to be crashed is reached. Consider crashing of job $A_{26}$ now. This also results in increasing total cost for each week of crashing.

To reduce the project duration, it is necessary to reduce the duration of the critical jobs. Consider critical job $A_{1}$, which can be crashed by 2 weeks at a cost of N320, 000 per week. This reduces the project duration by 2 weeks. The results are summarized in the Table 3 below: 
Table 3: Summary of Results

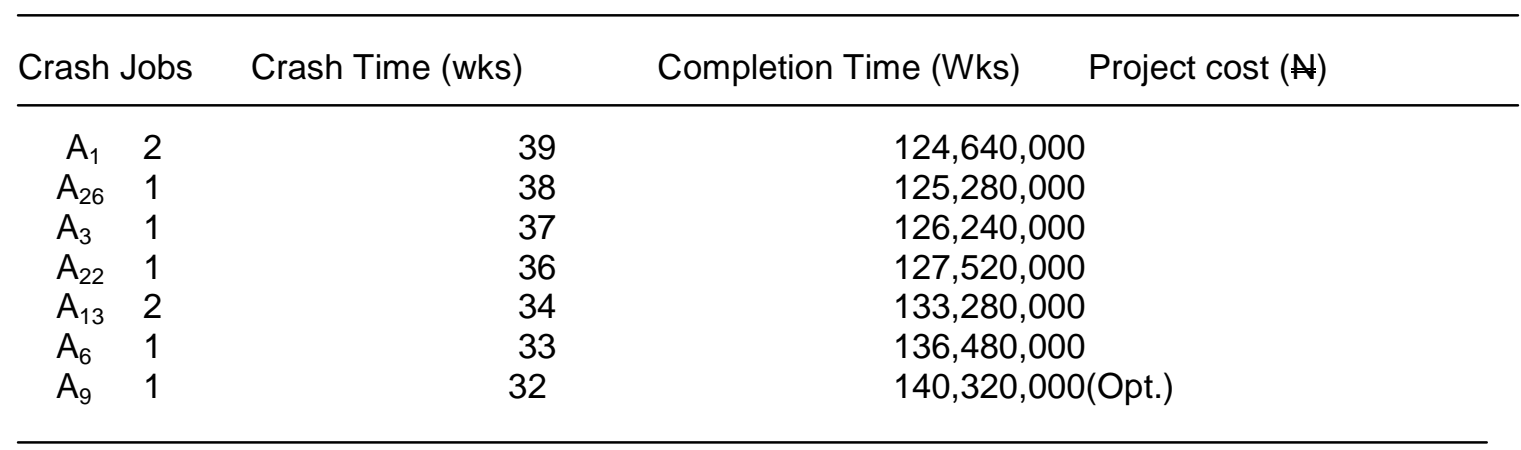

From the above table, we find that crashing $A_{9}$ alone is economical, because it has the least cost. No further crashing is economical. Hence the optimal project schedule is $A_{1}, A_{3}, A_{6}, A_{9}, A_{13}, A_{15}, A_{19}, A_{22}, A_{24}, A_{25}$, and $A_{26}$. The optimal length of the project is 32 weeks.

Very large projects will generally contain many parallel critical paths, and each critical path may have a large number of jobs. Examining all possible combinations of jobs in the parallel paths by the enumerative method will not only be inefficient but also expensive. For example, if we have two parallel paths with 10 critical activities in each, we will have to examine 100 combinations of jobs for possible crashing.

\subsubsection{Formulation of Mathematical Programming Model}

For large projects the mathematical programming methods are more efficient in determining the optimal project schedule. The linear programming model of this problem is given as follows:

Minimize :

$$
\mathrm{Z}=\left(d_{22}-d_{1}\right)+\sum_{(i, j)} C_{i, j}\left(y_{i, j}-d_{i, j}\right)
$$

Subject

$$
\text { to }: \begin{array}{r}
d_{j}-d_{i} \geq d_{i, j} \\
k_{i, j} \leq d_{i, j} \leq y_{i, j} \\
d_{i} \geq 0
\end{array}
$$

$$
\begin{aligned}
& \forall_{i, j}(\mathrm{i}, \mathrm{j}) \\
& \forall_{i, j}(\mathrm{i}, \mathrm{j}) \\
& \forall_{i, j} \mathrm{i}=1,2, \ldots 22 .
\end{aligned}
$$

Where,

$$
\begin{aligned}
& \mathrm{Z}=\text { Objective function } \\
& d_{22}-d_{1}=\text { The length of the project. } \\
& \sum_{(i, j)} C_{i, j}\left(y_{i, j}-d_{i, j}\right)=\text { Direct cost. } \\
& d_{i, j}=\text { The length of job }(\mathrm{i}, \mathrm{j}) . \\
& y_{i, j}=\text { Normal duration of job (i, j) } \\
& k_{i, j}=\text { Crash Time with the maximum amount of resources. } \\
& C_{i, j}=\text { Unit cost of shortening the duration of job (i, j) }
\end{aligned}
$$

$d_{i}=$ Event times $(i=1,2 \ldots 22)$ for a project consisting of 22 event. Where event 1 and 22 denote the start and end of the project. 


\subsubsection{Optimal Solution}

The above linear program has 48 decision variables, setting $d_{1}=0$, an optimal solution is found by the simplex method as

$$
\begin{aligned}
& d_{16,12}=0, d_{2}=d_{1,2}=d_{19,20}=d_{20,21}=d_{21,22}=1, d_{2,3}=d_{2,4}=d_{13,15}=d_{17,19}=2, \\
& d_{3}=d_{4}=d_{3,5}=d_{4,6}=d_{12,21}=d_{13,14}=d_{18,21}=3, d_{6,9}=d_{15,18}=4, \\
& d_{5,7}=d_{7,10}=d_{10,11}=d_{11,12}=d_{11,16}=d_{15,17}=5, d_{5}=d_{6}=d_{6,8}=d_{14,21}=6, d_{9}=d_{9,13}=10, \quad \text { The } \quad \text { optimal } \quad \text { project } \\
& d_{12}=d_{16}=d_{18}=26, d_{10}=d_{8,21}=16, d_{7}=11, d_{8}=12, d_{11}=21, d_{13}=20, d_{14}=23, d_{15}=22, \\
& d_{17}=27, d_{19}=29, d_{20}=30, d_{21}=31, d_{22}=32
\end{aligned}
$$

length is 32 weeks, and the optimum project cost is $N 140,320,000$.

\subsubsection{Determination of Floats}

Floats are the slack times available within the allotted span of the non-critical activity. The two most common floats are the total float and the free float. APPENDIXES C gives the convenient summary for computing the total floats $\left(T F_{i j}\right)$ and the free float $\left(F F_{i j}\right)$ for an activity $(i, j)$. The total floats are the excess of the time span defined from the earliest occurrence of event I to the latest occurrence of event $\mathrm{j}$ over the duration of $(\mathrm{I}, \mathrm{j})$. TORA is the software that was used to obtain the results both in terms of crashing to optimal results. The following are the steps and procedures for the systematic calculations involved:

\subsubsection{Earliest Start Time (ES)}

Allocate zero to the starting activity, add the duration of activity (expected time) to obtain the earliest start of the preceding activity, thereafter, add the duration of the activity to the earliest start of the preceding activity. Where two or more preceding activities are involved, add the duration of each activity to the earliest start of the preceding activities and select the maximum value.

\subsubsection{Latest Completion Time (LC)}

In the back ward pass, Starting from the final node, the computations proceed from right to left up to the beginning event. Thereafter, work backwards by deducting the activity duration from the earliest start time of the preceding activities. If there is more than one activity leave an event node, compute the latest completion time for that event.

\subsubsection{Total Float (TF)}

The total float for an activity is the difference between its maximum available time and its duration. It signifies the time by which an activity can be delayed without delaying the completion time of the project. A zero slack for an activity indicates that it cannot be delayed without delaying the project and hence it is called a critical activity. On the other hand, a positive slack for an activity means that the length of the slack can cause its without delaying the project and hence it is called a non-critical activity.

\subsubsection{Free Float (FF)}

Free float of an activity is the difference between its available time and its duration. Activity time was obtained directly from the chart (appendix A). However, slack times are inclusive. Successive application of CPM on the network diagram through the forward and backward pass yields the maximum completion time of the project and its associated cost. The results can be improved upon by crashing all the activities to its crash limit. Successive application of forward and backward pass will give the minimum completion time of the project and cost.

\section{Results}

The general results shows that the project was delayed. The project was executed at a staggering cost. No CPM plan was used. Uptil the time of this study the project has not been completed. CPM is a technique of planning; scheduling and controlling projects time and cost by recording their interdependence in a diagrammatic form that enables each fundamental problems involved to be tackled separately (Kothari 2003).

This research work applied CPM Method on the project. The following results were found. If all activities are carried out at their normal time, then the SMIT building will be completed in forty-one (41) weeks. The cost of the project is one hundred and twenty-four million Naira (Appendix B). On the other hand if each and every activity is executed at its crash time, then, the complex building will be completed in thirty-two (32) weeks. The cost of the project is one hundred and eighty-eight million Naira (Appendix C). There is a substantial saving in project time and cost to the tune of nine (9) weeks that is 22 per cent of time and forty- seven million; six hundred and eighty thousand Naira, which represents 25.36 percent of the cost.

The fundamental objective of CPM Study is to find the optimal completion time and cost of the project. When CPM is applied on the current solution (Appendix C) and necessary crashing is carried out the optimum solution is obtained (Appendix D). A computer application package known as TORA optimization system (Taha 2000) was used in the computation of CPM schedule. The optimal completion time is thirty-two weeks and the optimal cost is one hundred and forty million; three hundred and twenty thousand naira. The critical path is the path to watch if the project is to be completed on schedule, any delay in the execution of an activity on the critical path will delay the completion time of the entire project.

This will assist greatly in resolving crisis management. Crisis management is virtually eliminated by 
a pictorial representation of the total programme. It also promotes application of management by exception by identifying critical activities that are behind schedule for special attention. Appendix $B$ shows on page one normal time as original data. Activity symbol was assigned to identify an activity. Forward and backward pass computation results and bar graph were obtained using TORA Software.

Appendix $C$ shows on page one crash time as original data. Data was inputted into the computer package and yields forward and backward pass computations results and bar graph.

Appendix D produces the optimal results. All computation was carried out using TORA application package.

\section{RECOMMENDATIONS}

The study recommends that

i) All projects Nigeria must have a CPM plan. The initiator of the project must have a CPM plan for its execution. All tenders for the project must be accompanied by a CPM plan for its execution.

ii) Funds for the execution of a proposed project must be deposited with a bank before the contract for the project is awarded. During execution of the project funds should be released only according to $\mathrm{CPM} /$ cost plan.

iii) Severe penalties must be built into the terms of contract for delays in its execution. Similarly, reward must be given for the execution of projects ahead of schedule, provided the project is based on CPM plan.

iv) Concerned citizen(s) must be given the right, under the law, to prosecute government, its agencies and/or the executors of projects for failure to execute a project on schedule.

v) All government ministries and parastatals, including the presidency, must have an operations research/management science department to assist among other things in drawing up CPM plans for the execution of government project.

\section{CONCLUSION}

The aim of the study was to promote effective and efficient project management technique

Amongst private and public project executors. From the technical steps and procedure of diagramming and analyzing the network above, it can be seen that the ability of the network analysis in managing and controlling the project time and cost is not in doubt. The time analysis showed clearly the effect of delay on each and every activity on the entire

Programme, thereby making the task of resource management easier. Identifying the critical path too, makes the principle of management by exception possible, as the project manager can concentrate on the critical activities. The project came into life in the second week of august 2002 and up to the time of this study the project has not been completed. The project executors used Gantt chart instead of CPM. It is quite obvious that network based planning of critical path method (CPM) is superior to Gantt chart and similar project planning methods as it identifies the sequence and interrelationship of work tasks within a graphical network, enhanced interdepartmental communications, permit clear definition of responsibilities and identifies alternative methods of completing the project by concentrating on critical tasks and minimizing the incidence of crisis management on projects.

The study concludes that network analysis, specifically critical path methods (CPM) should be embraced in the planning and implementation of public developmental project in Nigeria, in order to overcome the problems of failure and abandonment of public projects.

\section{ACKNOWLEDGEMENT}

The author would like to thank anonymous referees for his valuable input and suggestions.

\section{REFERENCES}

Akinrinwale, I. O., 1990. Project planning in rural development programme: An appraisal of the plateau state integrated rural development programmers, Unpublished Bask Dissertation, University of Jos, Nigeria.

Bassey, K. J and Chigb, P. E., 2002. On building an orbased decisions model via coherent pluralism, Global journal of pure and applied sciences, 8, (3): 347-355.

Chasee, R. B and Acquilano, N. J., 1973. Production and operations management, Irwin Inc, Homewood (IL).

Cook, T M and Rusell, R. A., 1980. Comtemporary operations management: Text and cases, Prentice Hall Englewood Cliffs (NJ).

Idama, A., 1999. Operational research applications for management decision-making, 1st Edition, Paraclete, Yola.

Inyanga, I. N., 1999. Problems in government development monitoring and implementation in the development world: The Nigerian case, Journal of the project management technology futo, 2, (1): 132-135.

Kelly, J. E and Walker, M. R., 1959. Critical path planning and scheduling, Proceeding of the eastern joint computer conference, 1, 1-2.

Kidd, J. B., 1985. managing with operational research, $1^{\text {st }}$ Edition, Philip Allan, Oxford. 
Kothari, C. R., 1982. Introduction to OR, $3^{\text {rd }}$ Edition, Vikas pvt Ltd, India.

Lamela, L. S., 1990. Application of PERT in the construction industry: A case study of Gubi Dam construction project in Bauchi state, Unpublished M.B.A Dissertation, University of Jos, Nigeria.

Lee, S. M., Moeller, G. L and Digman, L. A., 1982. Network analysis, 3rd Edition, Pitman, London.

Loomba, P. N., 1978. Management: Quantitative perspective, Macmillan Inc., New York (NY).

Madugu Construction Company., Programme chart for the proposed school for management and information technology, federal university of technology, yola.

Moeller, G. L and Digman, L. A., 1981. Operational planning with VERT: Operations research, 29, 676-697.

Moder, J. J and Philips, R. C., 1970. Project management with CPM and PERT, 2nd Edition, Van Nostrand, New York (NY).

Nworuh, G. E., 2002. Network planning in implementation of public projects in Nigeria: empirical study, Interworld journal of management development studies, 1, (1): 265-275.

Percy, S., 1973. Advanced solvent: A network analysis program, Picatinny Arsenal Plans Office, 14, Dover (NJ).

Pritsker, A. A and Happ, W. W., 1966. Graphical evaluation review technique, Journal of the Operational Research Society, 18, 267-274.

Ravindran, A., Philips, D. T and Solberg, J. J., 1976. operations research, $2^{\text {nd }}$ Edition, John Wiley and sons inc., New York (NY).

Richard, B and Govindasami, N., 1997. Schaums outline of theory and problems of operations research, $2^{\text {nd }}$ Edition, McGraw-hill, New York (NY).

Taha, H. A., 2000. Operations research, $7^{\text {th }}$ Edition, Prentice-Hall, Upper Saddle River (NY). 